\title{
Finding Ourselves in a Predicament: Now What Do I Do?
}

Terrie Lynn Thompson, University of Alberta

Email: terrie@ualberta.ca

\section{Abstract}

Situations unfold around us every day in our professional and personal lives. We make decisions and move on, often acting out of routine or instinct. But sometimes we encounter an overwhelming sense of not knowing what to say or do and yet having to act. We are in a predicament. In this phenomenological inquiry, I explore the lived experience of a predicament, an experience that resonates with being stopped in our tracks, the illusion of using logic, indecision while in-decision, and drawing on knowledge of the moment. Experiential data in this study is integrated with Heidegger's notions of Befindlichkeit and Dasein, Ricoeur's writings on choice, and Gadamer's ideas about moral knowledge. Insights suggest that a predicament can provide a window for discovering something about whom and how we are. A predicament may be a self-conscious way of learning: a way of bringing ourselves to ourselves.

\section{Introduction}

Khalid, the driver of the car, turns to me with his intense eyes and stares at me expectantly. We are driving into the country for a special dinner. In the car are two local men - people I have worked with in the past two weeks. But I am now keenly aware that this is no longer an empty chat. As he steers the car, Khalid tells me how oppressive he finds his religion because it makes people accept the way things are and never challenge. He wants to know why religion in North America does not prevent people from moving forward. His dark eyes search my face. With a sinking heart and a clenching feeling in my stomach, I know I have to respond. But I do not know what to say. I do not know how to be in this situation or even who to be: Aid worker? Educator? Friend? Or just an empathic listener? I ask myself how I end up in these situations. Why is it that when people start to feel comfortable around me they want to discuss taboo issues that are politically dangerous? I gaze out the side window of the car. Yet even as I struggle with what to say, I feel excited. I am on unfamiliar terrain - in a foreign place, doing new things with no rules on which to rely. Khalid talks with passion. We both know 
something is unravelling and that he is revealing much more than the words he says. I do not know what is appropriate to convey. I try to respond in concise, carefully worded, politically correct sentences and hope he can read between the lines. I do not know the people in the car very well and am unsure how open I can be. My words ring hollow even to my own ears. As I watch the road, I feel Khalid's eyes continue to fix on me. I wish he would pay more attention to driving the car. I am barely aware of Raed, sitting in the back seat, until he leans forward in his seat. He says slowly, "These are heavy ideas. We do not normally speak of such things." A warning, I know. Once again, I do not know what to say.

It is now several years later. But this experience still haunts Leslie. Why? Because she was in a situation where she did not know what to say or do. Had she and Khalid just engaged in chitchat then she would probably have forgotten the whole event. Perhaps the foreignness and politically charged atmosphere makes this moment in the car with Khalid even more memorable. Leslie was experiencing a predicament, which can be defined as "a situation, especially an unpleasant, troublesome, or trying one, from which extrication is difficult" (Dictionary.com 2006).

Leslie felt caught in a situation where she had to do something. Although she sensed she needed to act, she did not know what to say or do. But Leslie seemed to have dealt with it, although she was, and still is not sure if she handled the situation properly. Perhaps she was not suitably prepared to deal with such unexpected and unusual predicaments in a cultural context that was so different from her own. But is it possible to prepare for predicaments? This question presumes that we know what the experience of predicament is all about. Leslie found herself in an unfamiliar environment and in a situation for which she did not have a ready-made response. But do these situations differ radically from predicaments that one may encounter in our more familiar lifeworld? Recently, I found myself in a situation of not knowing what to say or do.

My husband and I finally make the decision to move back to British Columbia. This has been a long time coming. We resolve to keep our decision to ourselves until we sort out whether we will live in Victoria or Vancouver; there is a compelling case for both. Later that day my mom phones. As soon as I answer, I know something is wrong. "I have some bad news. I have cancer." My heart skips several beats. Everything seems to grind to a halt and I sit down on the couch. My husband whispers, "What is wrong?" My parents live in Victoria. I tell my mom that we are moving back to British Columbia. She has been wishing for this for years and I hope this news will give her something positive to focus on. My husband takes one look at my face and frantically writes a note to me while I am on the phone, "Tell her that we're moving to Victoria." But I can't say this. And as my mother asks me where we will be looking for a house, I am silent. What do I say?

Was this a predicament? For my husband, it seemed to be more of a dilemma. He made a choice between two options, each laden with drawbacks, but he made a choice nevertheless. For me, it was not a matter of choosing. I did not know what to say or do. There was no deliberate tallying 
up of the advantages and disadvantages of various choices. Soul searching was required as I reckoned with my responsibilities to others and to myself. Action was demanded. It was important to do the "right" thing. But what was right in this situation? Was there a right response?

Situations unfold everyday. We make decisions and move on. Often we act out of routine or instinct. When someone throws something at us, we reach out to catch it or move out of the way. We do not spend agonizing moments deciding what to do. We act out of habit. But sometimes we encounter an overwhelming sense of not knowing what to say or do. Or we might face a difficult choice in which the options are not clearly defined or seem impossible, where there is an absence of choices, or we are in a situation that has gone past the point of rationally evaluating alternatives. What is it about a predicament that brings us to attention and sets this happening apart from all the other happenings in our day? Predicaments seem to spring out of everyday experiences - a car ride, a phone call. The predicament materializes as I answer the phone and come face-to-face with an unexpected turn of events. My mother's diagnosis is unanticipated, a shock. Still, I try to deal with it:

As I hang up the phone, I realize that this decision has become much more complicated. It is now no longer just about where we'd rather live or the best career opportunities. The next three weeks are gut wrenching. Any inner voice that could guide this decision has been silenced. I spend long hours staring at the river. Being near water usually helps me sort things out but it doesn't seem to be working. My mother, who lives in Victoria, has been diagnosed with cancer. How can I even hesitate to move to Victoria? Just when I think I know what to do a million other considerations jump out at me. And it's back to square one. I am consumed by this decision. Even my friends have given up. It seems everything has been said: every angle considered. One day as I sit on a rock by the river it finally comes to me. Yes, this is it. I know what to do. I feel happy, relieved, and peaceful. It feels right. I get up and start to walk down the path with a lightness in my step that has been absent for far too long. Then out of nowhere one niggling consideration emerges. How could I have forgotten about this? I stumble. With an overwhelming feeling of despair and helplessness I am now back to where I started; I have not decided after all. Work grinds to a halt. I have no appetite. I do not sleep. The weight of this decision is unbearable. Time is running out.

What do we do when faced with a predicament? It seems that we become acutely aware that we do not know what to do. And of course we try to get out of it. But the way out is unclear. It is like being thrust onto a stage without a script. During the car ride, Leslie had to cope "on the spot" with a situation that demanded spontaneity and improvisation. We try to manage these situations. But is this always possible? Perhaps our best hope is to "deal" with them. Despite our hesitation and doubt we are called on to react and respond. When faced with a decision about where to move I had more time to work my way out of this predicament than Leslie did in the car. But that did not seem to make getting "out" of the predicament any easier. When trying to decide where to move, I tried every decision-making strategy I knew but they did not seem to 
work. No matter how prepared we might have felt a moment ago, when we find ourselves in a predicament, we realize that we are, in fact, facing something unexpected and unique.

\section{Stopped in our Tracks}

By their nature, predicaments are disruptive. They address us. They force themselves upon us. Predicaments seem to upset the flow of our day, making it impossible to go forward until we deal with the situation unfolding around us. There is no escape. The car ride stopped being just a car ride. There was no going back to chitchat with Khalid's questions hanging in the air. The telephone call with my mother was no longer just a conversation. Whatever else I planned to do that day was set aside; in fact, I pushed everything else aside in the weeks that followed. A predicament catapults us into a different space and place. We are forced to grapple with a set of emerging circumstances that we neither anticipate nor want. The mundane is forced out of the picture. To use Langeveld's (1983) words, we are "encapsulated and submerged" (p. 5) as experienced by Rubina in the following situation:

I stay up most of the night perfecting my letter of resignation. There is absolutely no doubt in my mind. I want out. I knock on the Director's door. Glancing up she gestures imperiously to the couch. She finishes attending to her work. "So, Rubina, what is so urgent that it cannot wait?" What does she mean? I explained this to her last night on the phone. I expected her to say something like, "Oh my God, another incident?" But instead she reminds me impatiently that she has another meeting in 30 minutes. "So what is it that you want to say?" The scenario I had planned in my mind suddenly spins out of control. My body and mind go numb. Everything is now happening in slow motion except my mind which is spinning like a tornado. What's this all about? Why is she downplaying this? Now what do I do? I feel like yelling, "No!" at the top of my lungs. I desperately want to get this meeting over with. She takes my resignation letter, puts it on her lap, crosses her legs, and glares at me. "Well, I guess this is the end of you and the project." I'm puzzled, "I'm sorry. What do you mean?" She replies, "Well I can't run the project. I don't have the time. No one else is equipped. You go, the project goes, right?" I am not prepared for this reaction. She continues, "Tell you what. Take your letter. Think about it over the weekend. If you want to quit then I'll let everyone know on Monday." I feel trapped. Why can't she just let me bow out quietly? It's not ending.

This seems ordinary enough - someone decides to leave their job and prepares to hand in their resignation. Rubina was determined to quit. She had it all planned - what she was going to say, what the Director would say, how she would nod in agreement. She even wore a special perfume for the good-bye hug she was certain to have with the Director. This is not a predicament. Yet, Rubina's expectation of how events will unfold suddenly crumbles as the situation around her reconfigures itself into something completely different. When this happens she is propelled into 
an unexpected moment - she is in a predicament. The Director's response stuns her. This new set of circumstances demands a totally different response. She struggles to improvise. Predicaments are impervious to planning and preparation. When the other refuses "to be contained in the conceptual apparatus that I have prepared for it" (Bruns, 1992, p. 180), a roadblock is thrown in one's path. In that refusal, we struggle to understand and make sense of what is going on.

Rubina's planning did not help when the certain became very uncertain. She seems to be experiencing what Gadamer (1989) refers to as "being pulled up short" (p. 268), something that may happen when our "assumptions, expectations, and desires fail to materialise, are thwarted, or reversed" (Kerdeman, 2003, p. 295). Being pulled up short, stops Rubina in her tracks. Then she starts to panic. As Kerdeman explains, when we are caught off-guard in this manner, our "'knowhow' and its accompanying sense of security and control" are challenged (p. 296). Can Rubina now leave without jeopardizing her career and reputation? This was not how it was supposed to go. She does not know what to do. She feels her life grinding to a halt. Until she gets out of this predicament, the rest of her life is on hold.

And yet, perhaps predicaments find us because we are open to them. Gendlin (1979) writes that "we don't come into situations as if they were mere facts, independent of us. We have had some part in getting ourselves into these situations ... and the mood has the implicit 'understanding' of all that" (p. 45). This is the mood Heidegger (1962) refers to as "our Beingattuned" (p. 172). Arising out of Being-in-the-world, the mood of Dasein is already disclosed and "makes it possible first of all to direct oneself towards something" (p. 176). Although Rubina's predicament seemingly arose out of thin air, being "pulled up short" might have occurred because this situation and what was happening mattered to her. It was grounded in her state-of-mind, which revealed itself enigmatically as the situation unfolded and revealed itself. As Gendlin explains, Dasein is a "being-in and being-with that is fundamentally open to events" (p. 61).

\section{The Illusion of Using Logic to Control}

The way out of a predicament is not straightforward. Extricating ourselves is difficult. Can we truly think our way through these situations? When we find ourselves in a predicament, our first recourse may be to appeal to our intellect to sort it out and solve it. When I heard my mother's news, I first attempted to "manage" the situation. Despite my best efforts to weigh the benefits and disadvantages, explore my feelings, talk it through with friends, and listen to my inner voice, I seemed unable to "manage" this predicament of where we would live. It consumed me. There was no routinized response or handbook for reference. Regardless of my intellectual tactics, I felt I was losing control of the situation.

When we turn to logic we may realize, to our dismay, that it often lets us down or is not useful. Ricoeur (1950/1966) writes that "intellectualism pretends to believe that only one series of thoughts unfolds its implications ... [whereas] the truth is that we must constantly orient ourselves in a maze of intersections and badly marked roads" (p. 159). Perhaps we end up "feeling" rather than "thinking" our way out of the maze of the predicament. Gendlin (1979) refers to feelings as "sensed complexities" (p. 53). Logic - intellectualism - did not seem to be of 
much use to Leslie when sitting in the car and the conversation took an unexpected turn, although she attempted, fleetingly, to figure out her role. She had enough know-how to realize that she should be cautious but this did not tell her what she should say. In this situation, she did not "design" her actions as much as tried to "sense" and "feel" the subtleties and complexities of the atmosphere in the car. Perhaps the unsettling that is experienced in a predicament is because these situations create an opening for messy emotional responses that draw on feelings; quite different from a calculated cognitively logical response.

Although we want to do the right thing, knowing the "right" response can be elusive, if not impossible. Gadamer (1989) emphasizes the importance of moral knowledge, a "deliberating with oneself" which "can never be knowable in advance like knowledge that can be taught" (p. 321). Predicaments seem to call on us to deliberate with ourselves. In the following passage, Amy knows on an intellectual level that she has important information and yet cannot share it with the very person who needs to hear it. She wrestles with the ramifications of speaking up. She grapples with what is un-knowable in advance and only know-able in the moment Gadamer's moral knowledge. Gadamer writes that

Although it is necessary to see what a situation is asking of us, this seeing does not mean that we perceive in the situation what is visible as such, but that we learn to see it as the situation of action and hence in the light of what is right. (p. 322)

Logic will not get Amy out of her predicament. She might not see everything there is to see in this situation, but her response resonates with a realization that action is needed and that doing the "right thing" is important.

I am torn. Jim is now very sick. I don't think this hospital is equipped to deal with him. He needs to see a pulmonary specialist. He needs to be moved to the renowned transplant hospital 100 miles away and have a lung transplant. Should I say something? What would I say? Is this any of my business? When my friend, Fern, told me that her husband, Jim, had been diagnosed with severe cardiopulmonary disorder I found out as much as I could. I've always played a big sister role to Fern, sharing what I know. However, I hold back. Although the doctors tell her that he'll pull through, I do not believe this. Is it right for me to tell her what I think I know? After all, I don't want her to lose hope. Part of me doesn't believe what I have read on the Internet anyway. Jim can't have only a few years left to live. Do I really feel that confident in what I know? Do I want this responsibility? As I sit with Fern at the hospital my deliberations intensify. Time is suspended. I look for practical things I can do to stop the questions running endlessly through my mind. I wait for an opening that never seems to come. In the end I say nothing. What I do is loan Fern my sweater. She had said she was cold so I bring a big fuzzy sweater from home. It's soft, like a hug. As I look at her I know this is the right thing to do. Three days later, Jim passes away. 
Amy's predicament started when Fern calls and tells her about Jim's diagnosis. Amy is stunned by this news. As soon as she hangs up the phone she goes on the Internet to find out as much as she can. Reading one document after another, she suspects that his prognosis is bleak and that he may need different treatment in a different hospital. In that moment, she feels stuck, wondering what to do and what to say. She hesitates, unsure how to proceed and sees no obvious way out. She is caught in Ricoeur's (1950/1966) maze with no clear-cut alternatives; there is no one clearly marked path that can be discerned by intellect. For Amy, rationalizing the best course of action on an intellectual level is no help. The more she rationalizes, the more she hesitates, and her predicament is prolonged. This hesitation described by Ricoeur, is both "falling short of a decision" as well as being "an attempt at choosing" (p. 137).

While she understood logically that she might have important information, something held her back. Her heart, gut, or soul - somewhere deep inside her - knew something her head did not. Although her mind was bombarding her with questions, doubts, and directives, Amy "felt" her way through this predicament day-by-day, drawing on her feelings in the moment for cues in a quest to do the "right" thing. It seems that a predicament demands a more improvised, emotional, "from the gut" response rather than a careful weighing of alternatives. Predicaments remind us that there is no certainty of control.

\section{Indecision While In-Decision}

We make choices everyday through instinct, habit, and routine. We are barely conscious of many of these choices. When another car cuts us off while driving it is unexpected and yet it is not a predicament. Most drivers have several options in their repertoire. They choose one and move on, often without great effort on their part. This does not seem to be so with a predicament. Suddenly we cannot act out of habit. There is no normal, no automatic response, no ready-made routine. Instead, we hesitate and doubt. And then we deal with it, doing whatever we can to respond. Sometimes we are forced to react immediately, as Leslie did in the car when the conversation took an unexpected turn. But sometimes we hesitate, hoping that we will be able to figure out what to do if only we had a bit more time to feel and think our way through the situation. This is what happened when I learned about my mother's diagnosis. While my husband was able to respond immediately, I could not. As I hesitated, I flailed around looking for options and insights. I experienced hesitation described by Ricoeur (1950/1966) as "a choice being sought" (p. 137).

Amy did eventually make a choice. But what is a choice? Ricoeur (1951/1978) writes that "a choice is only a cessation of deliberation, the coming to rest of attention." He adds that choice can also be regarded as "an upsurge, an irruption of existence" (p. 107). In the end Amy focused her attention on what she could do - this is what mattered. She decided to bring Fern a sweater so she would not be cold. She said nothing. Her deliberations ceased. But she also experienced an irruption, a new awareness of herself and the situation because of what she risked as she improvised and how she understood her personal boundaries.

Do predicaments necessarily entail a decision or choice? Sometimes we seem to find ourselves in a predicament because there are no tangible options in the moment. We struggle to 
face what seems inevitable when what we really want are choices and the power to make a decision. And so we experience what Ricoeur (1950/1966) calls our "im-possibility" rather than our possibility (p. 138). In each of the anecdotes, the individuals feel powerless, helpless, and vulnerable as they wrestle with the situation into which they have been inserted.

Deciding where to move was a big decision. But when I heard my mother's news things seemed to spiral out of control. I did not know what to do. I felt I had lost my center. I did not feel right. This is the painful self-loss that Ricoeur (1950/1966) suggests we experience in indecision: "In hesitation I am many, and so am not" (p. 137). Nevertheless, I knew I would find my way out. I still had room to manoeuvre. I would deal with it. This knowing seems to distinguish a predicament from other difficult situations like a crisis. In a crisis, such as a death in our family, things shut down - we may feel paralyzed and see no way out. Amy was in a predicament that was deeply distressing. Although this situation left her upset and unsettled, she knew she could deal with it; she would get un-stuck. Perhaps in a predicament our efforts are focused on trying to deal with it and find our way out of it. And we know we will. But in a crisis, we cannot change what has happened, we cannot make it better, and moreover, we may not be able to deal with it for a long time, even a lifetime.

\section{What Do I Do Now? Drawing on Knowledge of the Moment}

Being in a predicament is like being "in" a corner, a pickle, or a tight spot; words that suggest being stuck, caught, or trapped. We want to get out of it - it's awkward, uncomfortable, disconcerting. We feel unbalanced, out of our element, unsure, tentative. But how do we actually get "out" of a predicament? Is it always a conscious, deliberate, willed act? Or is it a more subtle recognition that something is different? For example, waking up one morning and realizing that we have come to peace with something bothering us, even though we might not really know how we came to a sense of resolution.

Predicaments are filled with uncertainty. A predicament seems to be an emergent indeterminate state of affairs. It is filled with agitation and restless, relentless questioning and speculation: What's going to happen now? What do I do? What should I do? How will I ever get out of this? Why is this happening to me? A memory from a time when I was working in the Middle East presses itself on me. This was another predicament that left me speechless and immobilized for a time until I was able to somehow create knowledge in that moment to get unstuck. It is a hot day ...

Masa leads me into the office for a private conversation and I know something is afoot. Private conversations are uncommon in the middle of the day in this office. We sit facing one another. I'm unsettled. Masa says, "The team has something they need to tell you." Now what? I know this project is a challenge. Oh my God. What if they back out? How will I ever explain this to the Director? But Masa says, "It's about Lina." I nod. Yes, something is not right with Lina, the key facilitator in this project. I have been puzzled by her behaviour which has become erratic and distracted. I have been worried as the success of this step in the 
project depends on her work. This morning she showed up looking like she hadn't slept, was unprepared, and she struggled to make sense of what was going on today. But as I listen to Masa's words everything in the office fades away except for her voice. Masa speaks matter of factly. Lina has just learned that her father has threatened to kill her when he is released from prison because she testified against him. As Masa finishes the story, she looks at me. What do I think we should do? I am stunned. This is horrible beyond words. How do I handle this? What is even possible? When I signed on for this contract, never in a million years had I imagined I'd be faced with this kind of situation. All I can think to say is "Oh my God."

We bring knowledge and skills but more importantly, we bring attitudes, dispositions, and ways of regarding the world to any everyday situation. But how useful is all of this when we are suddenly propelled into an "I've never been here before" moment? In this story, this moment was familiar yet unfamiliar. As Kohak (1996) says, I was "stuck with the particularity of my situation" (p. xxiii). I have been in challenging situations but never before in this unique circumstance. I had not read any guidelines that prepared me for how to respond. I had no time to construct a strategy, yet, I somehow managed to "get out" of this predicament. Words came out of my mouth and I heard myself saying, "How can we help Lina? What do you think is the best way to approach this? Should we cancel the rest of this event?" I'm not sure where these thoughts came from. I wonder how I could sound so in control when inside it felt like there was no space, no time, no sound.

We do what we can to get "unstuck" and somehow we get through a predicament. This predicament created a sense of dissonance. Somehow, I built knowledge and know-how in the moment to get "out" of this predicament. Even if I had been given all the time in the world to come up with a strategy I doubt I would have had any better insights into what to do. Perhaps we forfeit some of our pre-determined knowledge in exchange for knowledge of the moment as we make choices. Ricoeur (1996) suggests that choice "is a fixing of attention" (p. 149). As we fix our attention, we find the know-how in the moment that we need to deal with the predicament. How does this knowing in the moment materialize? Ricoeur suggests that "attention is something that unfolds in time, accentuating and bringing to light various alternative 'aspects' of a disordered situation, the diverse 'value aspects' of a practical puzzle" (p. 157). In my conversation with Masa, my attention fixed on Lina and what we could do to help her, regardless of the consequences for the program.

When we find ourselves in unexpected and new situations, we pull from both the world around us and from inside us. Is it possible that we can draw from the situation itself? If so, it seems our knowledge of the moment - the knowledge we need to get out of the predicament - is situated in the predicament itself. This makes sense if we consider Gadamer's (1989) suggestion that we cannot stand apart from the situation itself, the world, or even ourselves. And therefore the knowledge of the moment that is needed is indeed there with our being there - part of life. Ciborra (2001) writes that "situated knowledge is always moody knowledge" (p. 3) therefore "before action and before design there is a being thrown into a range of possibilities. [Your] mood situates you in respect to these possibilities, discloses some and conceals others" (p. 12). 
Although we may be surprised when "thrown" into a predicament, we are never entirely unprepared or without the "tools" that we require in the situation, as clumsy as they might seem to be in the moment.

\section{Revealing Ourselves}

The Oxford Concise Dictionary explains that the word "predicament" comes from the Latin praedicare - prae meaning 'beforehand' and dicare meaning 'make known' (Pearsall, 1999, p. 1126). In this sense, a predicament can mean the thoughts and feelings we wrestle with before we act; before we make our choices and words public. A predicament, therefore, forces us to expose ourselves. Our inner turmoil is eventually revealed and becomes susceptible to judgement. Moreover, our response, how we handle the predicament, reveals us. Perhaps a predicament emerges when we have something at stake and realize how much it may reveal. A predicament is a predicament because the unfolding events and the outcome matter to us.

When we find ourselves in a predicament, we are suspended in the moment. Engaged. Predicaments seem to have a way of enveloping us - bringing us totally into a moment. Langeveld (1983) talks about "one is with oneself. ... one finds oneself in the unexpected presence of one's own self without having tried to make oneself a project of study" (p. 2). The predicament of moving to British Columbia was consuming. I was suspended in the moment. Although it was a painful and uncomfortable experience, I was engaged. Everything else in my life faded into the background as the lens zoomed in and focused on this particular situation, a moment in time I remember even now with a surprising degree of clarity and vividness. There is something about a predicament that embodies us. We reveal ourselves to ourselves. Leslie was totally in the moment during that car ride. And although difficult and troublesome, it was exciting to be in a situation doing new things with no rules on which to rely. She was breaking through habit and the familiar and learning how to be in an especially novel way.

Predicaments are unique and personal. One person's predicament may not be an issue even worthy of a second thought for someone else. With growing dismay Rubina saw her escape route slipping away. She just wanted to quit. Her feelings about the untenable nature of her position countered against a sense of responsibility to see the program through and get the credit she deserved, created a predicament for her. Another person may have reacted very differently in this situation. For another person, this may not have been a predicament at all. Gendlin (1979) writes that people "live-in a world they themselves define with their living in" (p. 47). A predicament is very much grounded in the particular. Therefore, it is not only an unexpected turn of events or perceived severity of the situation that creates a predicament. We are also actors in these situations. The Houghton Mifflin Canadian Dictionary states that a predicament is "a specific state or condition" (Morris, 1982, pp. 1031-1032). Perhaps being in a predicament is ultimately feeling that we are stuck in a situation. This feeling of "stuck-ness" seems to be as important as the nature of the circumstances themselves.

Ciborra (2001) states that, "a situation is defined by both emerging circumstances of the world, and by the emerging situation of the actor" (p. 3). Heidegger refers to Befindlichkeit, which often is interpreted as "mood." This is not a mood that we bring to the situation and it is 
not a background for what happens. Every situation already has a feeling; a tone and mood of being in the world. Heidegger (1962) explains that, "it comes neither from 'outside' nor from 'inside,' but arises out of Being-in-the-world, as a way of such being" (p. 176). It seems that a predicament is not only a set of circumstances that unfolds around us but also the mood that infuses a situation and our being-ness. Befindlichkeit "already has its own understanding ... it is sensed or felt, rather than thought" (Gendlin, 1979, p. 45). Heidegger states that, "in this 'how one is,' having a mood brings Being to its 'there"' (p. 173). The tonality of moods, therefore, seems to make it possible for two different people or even for us, at two different moments in our lives, to perceive and respond to a situation in very different ways. In the room with Masa the atmosphere was charged. This was no ordinary meeting I walked into, already uncertain, doubtful, and a little off balance. Perhaps someone else, or myself at another point in time, might have experienced a different Befindlichkeit and then maybe what unfolded would not have been a predicament.

\section{Lingering}

A predicament may be irresolvable. Predicaments can haunt us. Although we dealt with it in the moment, we may be unable to put it in a box and keep the lid closed. A predicament is not always easily dismissed. Amy's choice to give Fern a sweater signaled the end of her deliberation, but perhaps not the predicament. Amy shares how she feels now about her decision to not say anything about the information she thought she knew about Jim's disease:

I didn't say anything. Now it is too late. I never expected him to die. The decision about whether or not to say anything was never about saving his life. I didn't know the stakes were so high. Jim passed away 5 years ago and it still comes back to me. To this day, I still don't know if what I did was right or wrong.

Sometimes we get out of a predicament only to find that we are still uneasy and agitated; it seems we are still in it. It is like a tape that plays itself over and over and we are unable to push the stop button. Sometimes we need distance in time and space from the event for the intensity to fade so that we can make sense of what happened. Until we do, the predicament seems to live on. What is it about predicaments that tug at us days or even years afterward? Perhaps predicaments force us to confront a difficult reality. Amy still wonders if she made the right decision and what she would do if she was in that situation again. When will her predicament end? Even though the moment of uncertainty passes, some predicaments linger. When you think back on what happened, you wonder; if you were to find yourself in this kind of situation again do you know what you would, should, or could do? When Leslie thinks back to her experience in the car, even now she does not know that she could react any differently when faced with that kind of conversation. She would like to believe that it would not be so difficult "next time." But who knows? We may know ourselves better but if we run into this kind of situation again would we react any differently? 


\section{So Now I Wonder ...}

We speak of finding ourselves in a predicament, just as we might say that we found ourselves going to the Jazz Festival on the weekend. Perhaps it is in a predicament that we actually "find" ourselves. We experience a self-revelation as something of who we are is revealed and discovered. When confronted with a predicament we become acutely aware that something new or different is happening. Owing to its disruptive and tumultuous spirit a predicament may become a turning point. We may be left with a question or perhaps a settling or discovery. Perhaps a predicament sparks reflection or launches a learning initiative. Despite being rife with difficulty and uncertainty, a sense of knowing and confidence about our selves may emerge.

Perhaps a predicament is a very self-conscious way of learning; a way of bringing ourselves to ourselves. Bruns (1992) writes that

It is not always the case that ... one understands something in the sense of grasping or solving it. What happens, also or instead, is that one always confronts the limits - in Gadamer's language, the finitude or historicality, the situatedness of understanding itself. (p. 180)

We may surprise ourselves with what we can do. We may discover our limits, our finitude. Perhaps we learn more than we bargained for or anticipated. Gendlin (1979) writes that in the "being-in what happens" we find and constantly retrieve ourselves, "so that there is a present in which our capacity to be is again and again our own" (p. 62). This is Heidegger's notion of authenticity. The nature of a predicament may provide a window for discovering something about whom and how we really are.

But is there more to this than a re-presentation of who we are to ourselves? Gadamer (1989) writes that "self-understanding always occurs through understanding something other than the self, and includes the unity and integrity of the other" (p. 97). In their ability to interrupt, predicaments seem to create the spaces to re-insert ourselves into our relations in the world: providing entry points to life. Amidst the mundane, familiar and everyday, predicaments may shake things up and enable us to "find" ourselves and experience Dasein, 'being-in-the-world,' in a very real and visible way.

\section{References}

Bruns, G. L. (1992). Hermeneutics: Ancient and modern. New Haven, CT: Yale University Press.

Ciborra, C. U. (2001). In the mood for knowledge. Retrieved March 9, 2006, from http://www.lse.ac.uk/collections/informationSystems/pdf/events/2001/ciborra.pdf

Dictionary.com (2006). Retrieved January 11, 2006, from http://dictionary.reference.com 
Gadamer, H. G. (1989). Truth and method (2 ${ }^{\text {nd }}$ Rev. ed.). New York: Crossroad Publishing.

Gendlin, E.T. (1979). Befindlichkeit: Heidegger and the philosophy of psychology. Review of Existential Psychology and Psychiatry 16(1-3) 48-60.

Heidegger, M. (1962). Being and time (J. Macquarrie \& E. Robinson, Trans.). London: SCM Press.

Kerdeman, D. (2003). Pulled up short: Challenging self-understanding as a focus of teaching and learning. Journal of Philosophy of Education, 37(2), 293-308.

Kohak, E. V. (1966). Translator's introduction. In Ricoeur, P., Freedom and nature: The voluntary and the involuntary (E. V. Kohak, Trans.). Evanston: Northwestern University Press.

Langeveld, M. J. (1983). The "secret place" in the life of the child. Phenomenology + Pedagogy 1(2), 181-189. Retrieved February 16, 2006, from http://www.phenomenologyonline.com/articles/langeveld2.html

Morris, W. (Ed.). (1982). The Houghton Mifflin Canadian dictionary of the English language. Boston: Houghton Mifflin Canada.

Pearsall, J. (Ed.). (1999). The concise Oxford dictionary (10 ${ }^{\text {th }}$ ed.). Oxford: Oxford University Press.

Ricoeur, P. (1966). Freedom and nature: The voluntary and the involuntary. Evanston: Northwestern University Press.

Ricoeur, P. (1978). The unity of the voluntary and the involuntary as a limiting idea. In C. E. Reagon \& D. Stewart (Eds.), The philosophy of Paul Ricoeur: An anthology of his work (pp. 93-112). Boston: Beacon Press. 